American Journal of Applied Sciences 9 (10): 1625-1635, 2012

ISSN 1546-9239

(C) 2012 Science Publication

\title{
Edge Glued Wood Panel Technology and an Assessment on the Development of Edge Glued Wood Panel Industry
}

\author{
Tuncer Dilik, Seda Erdinler and Ahmet Kurtoglu \\ Department of Forestry Industry Engineering, \\ Faculty of Forestry, Istanbul University, 34473 Bahcekoy, Istanbul, Turkey
}

\begin{abstract}
In this research, it is aimed to determine the general situation of edge glued wood panel industry that is rapidly developing in Turkey with the reasons of this development similar to the development edge glued wood panel industry in the world. Besides, starting from its definition, there are information about edge glued wood panel, comparison with other panel products and technology preferences of production. As the result of this study, there are 3 essential reasons of the rapid development of edge glued wood panel industry in Turkey. These are; (1) Environmental health and ecological approaches as a movement of thought having impact on the consumer behaviors and rapidly improving throughout the world, (2) Having less production and investment cost compared to the other wood based material production and investments and (3) In addition to the advantages owned when compared to the other wood based materials, having the production technology involving flexible production systems to respond to every demand level. According to the data related to edge glued wood panel demand and supplies, the production of edge glued wood panels replace to East Europe where there is also Turkey. It is determined that investment and cost of Turkish edge glued wood panel are mainly in Marmara region (43.3\%) and raw material (43\%) respectively. $67 \%$ coniferous and $33 \%$ broad leaved tree species are used in Turkish edge glued wood panel production. The most preferred edge glued wood panel thicknesses are 16, 19, 30 and $42 \mathrm{~mm}$. The technological preferences of the manufacturers depend on their machines and production line with optimization systems where as the users' preferences are price and quality by $90 \%$. It is determined that with its structural condition, the sector is open for investment and development.
\end{abstract}

Key words: Solid wood panel, edge glued wood panel production, quality classes of edge glued wood panel, technology preferences

\section{INTRODUCTION}

The tendency to the wooden panel industry has moderately increased in the recent years in order to meet the high production demand and the product variety improving as parallel to the technologic and economic development. It is seen that the productions of particle board, MDF, melamine coated particle board, plywood and OSB, products have increased intensively since 1990 . The reason why these types of products are selected is that in addition to the demand of the market, they are appropriate for mass production and have homogenous structures. Furthermore, the moisture differences and physical, mechanical and technological properties changing per the faults, problems are less seen in the solid wood materials and therefore these constitute the reasons why the wooden panel products are preferred (Nicholls, 2010; Dilik, 2009; Smith and Araman,1997; EPF, 2006).
On the other side, particularly starting from the 1990s and as of the beginning of 2000s, the solid wood material started to be more stabile like in the panel industry and to be used in a faster and more practical manner in the furniture industry as compared to the past with the aid of the developing technology. These developments have oriented the manufacturers, who were having more tendency to the panel industry, to the edge glued wood panel production due to the production time in the solid wood as well as the challenges in the product practices.

The conscious consumption and the ecological approaches improving together with the living standard increasing in the world were important factors in the rapid raise in the utilization areas of the edge glued wood panel furniture and wood works industry (Bilgin, 2010; Dilik, 2005; Smith and Araman, 1997, EPF, 2005). Parallel to this, it has become an industry that

Corresponding Author: Tuncer Dilik, Istanbul University, Faculty of Forestry, Department of Forestry Industry Engineering, 34473 Bahcekoy, Istanbul, Turkey Tel: +90 212 2261100, Fax: +90 2122261113 
provides employment to reach to high production capacities at high rates both in the world and in Turkey.

While the number of edge glued wood panel factory in Turkey was 1 in year 1990, it has been determined that the number of the factories increased to 30 in year 2010 and this shows that the industry is in a rapid growth (Bilgin, 2010). This case reveals that due to the increasing lack of raw material in the forestry industry throughout the world, the solid wood material is now being preferred in places where other panels are used as well it is a rapidly developing industry with its advantages in terms of esthetic, naturality, functionality and applicability particularly in furniture and door industry.

\section{MATERIALS AND METHODS}

In this study where the reasons of development in the edge glued wood panel technology with structural situation and the development of Turkish edge glued wood panel industry were investigated, the method based on observation, face to face meeting and current research data.

Within this frame; the information and findings obtained from the comparison of edge glued wood panel with other wood based panels, the technology preferences in the edge glued wood panel, the utilization areas of edge glued wood panel, the quality classifications, the specifications and dimensions of edge glued wood panel preferred in production, the wood species preferred in production and their utilization rates, the cost factors in the edge glued wood panel production, the production capacity of Turkish edge glued wood panel and its regional allocation as well as the other terms concerning the selection of edge glued wood panel, have been assessed and the results were obtained.

\section{Findings:}

Definition of edge glued wood panel and its comparison with other wooden materials: The edge glued wood panel is defined as the panels obtained by gluing small section of solid wood parts, in other words lamellas, made of same wood type while they are in single part mode or edge glued, particularly as to let the fibers to be parallel to each other and as to be glued in single layer through horizontally and vertically from the edges (Dilik, 2005).

The utilization of edge glued wood panels is getting wider both because of the superiority of the solid wood material on the other materials and its specifications to meet any kind of requirement with its high dimension and dimensional stability as well as its structural physics. By regards of utilization, it is used and recommended as an alternative to the other panel products particularly in the furniture and decoration works with its easier production and economy providing specifications both in the production and quality control. However, some conditions are required for the expected specifications of edge glued panels. Today as it can be said for all industry branch, it is critically important to manufacture a product in an economic manner in addition to the quality of such product due to the developing production systems. Therefore, it should be kept in mind that the way to have the best result in the edge glued wood panel is to realize the production and quality control within the frame of the targets of the investor under the certain principles and conditions (Dilik, 2005; Özkaya, 2007).

The wood material is always the primary material of the wood works and furniture industry as solid wood and veneering sheet. For this purpose, some properties required in the solid wood material to be used can be listed as following (Kurtoglu, 2010):

- Good appearance, color and texture superiority

- Easy machining and smooth surface

- Appropriateness for surface finishing

- Being resistant to fungi and insects

- Being knot-free and having straight grain

- Being resistant to climate conditions

- Having low shrinkage and swelling degrees

The edge glued wood panel has been developed as an alternative to the wood based panels (particle board, plywood, MDF, OSB,...) that are developed or continued to be developed within the time for meeting such specifications required for the wood works and furniture industry and it can be easily used at the required quality and customer satisfaction in each field where the other wood based panels are used. In addition, concerning the utilization areas, it has some advantages and disadvantages as mentioned in the Table 1 (Dilik, 2005; Nicholls, 2010).

Development of edge glued wood panel industry in Europe: As a result of the performed surveys, it was observed that the edge glued wood panel industry's fast development in Europe results from 3 main reasons. These are:

- The consumer behavior that is valid in all production industries against environmental health and ecological approaches as a trend rapidly improving throughout the world

- Having less production and investment cost as compared to the other wood based materials

- In addition to the advantages owned as compared to the other wood based materials, having the production technologies involving flexible production systems to respond to every type of demand 
Am. J. Applied Sci., 9 (10): 1625-1635, 2012

Table 1: The advantages and disadvantages of edge glued wood panel compared to other wood materials

\begin{tabular}{ll}
\hline Advantages & Disadvantages \\
\hline $\begin{array}{l}\text { 1-The solid wood material provides a wider surface } \\
\text { without disturbing the naturality and is a material } \\
\text { ready for direct utilization. }\end{array}$ & $\begin{array}{l}\text { 1-Its dimensions shrink or swell through } \\
\text { gaining or giving moisture due to the } \\
\text { relative humidity and temperature } \\
\text { changes in the climate conditions. }\end{array}$ \\
$\begin{array}{l}\text { 2-Has rich texture, color and decorative appearance. } \\
\text { 3-Has high dimension stability and resistance features. }\end{array}$ & $\begin{array}{l}\text { 3- Not resistant against the harmful fungi and Insects. } \\
\text { 4- Has faults affecting the stability } \\
\text { 4-Is more advantageous in disassembled furniture }\end{array}$ \\
$\begin{array}{l}\text { production compared to other panel products. } \\
\text { 5-Has high surface stability and appropriateness for }\end{array}$ & \\
$\begin{array}{l}\text { the surface coating and upper surface finishing and } \\
\text { superiority for edge banding (processes like coating, } \\
\text { banding, edge stripping, are not required) }\end{array}$ & \\
$\begin{array}{l}\text { 6-Having many different dimension and type options with its uniform thickness, } \\
\text { its easy machinability in the machines and being a material with long life. 7-Having }\end{array}$ & \\
low investment cost compared to the other panel products (when compared to \\
mdf,partical board, plywood, factories, it has approximately 10 times less investment cost.
\end{tabular}

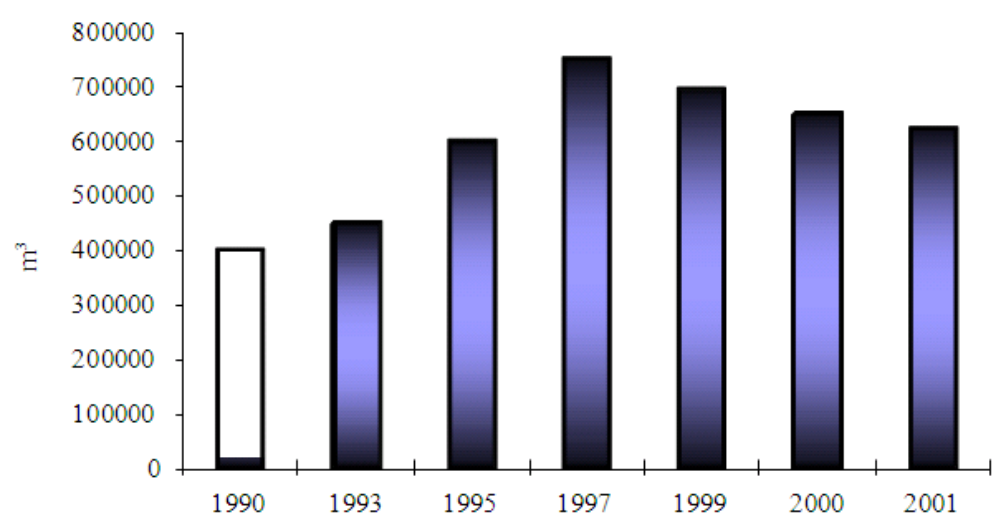

Fig. 1: Development of edge glued wood panel production in Europe per years (Dimter, 2005)

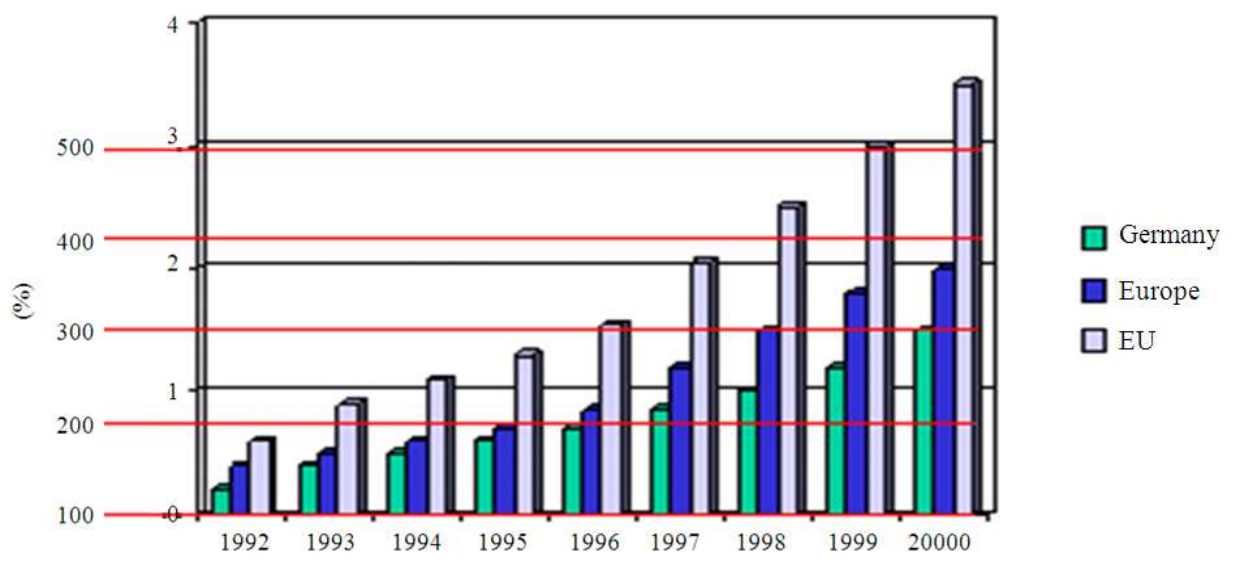

Fig. 2: The development of edge glued wood panel demand in Europe per years (Dimter, 2005)

Although the manufacturers of particle board, mdf, OSB, plywood, wood based panels in the world have associations or unions, it is seen that the edge glued wood panel manufacturers are not placed in such unions or even they do not have their own associations or unions. Therefore, the official statistical data concerning the edge glued wood panel supply and demand are not sufficient. However, some private 
organizations (Dimter, 2005) have surveys on this topic. The improvement of the edge glued wood panel market has tried to be explained below with the results of this survey that has been performed as to cover the years 1990-2001 for the edge glued wood panel industry in Europe (Dilik, 2005; EPF, 2005).

It is seen that Red Pine-Spruce (80\%), Black Pine $(11 \%)$ and Scotch Pine $(7 \%)$ are used as coniferous tree for the edge glued wood panel production in Europe and Alder (43\%), Fagus (36\%), Betula Pendula (10\%), Silverbirch (7\%) and Oak (4\%) are used as broad leaved tree. This case for Turkish edge glued wood panel industry has been determined according to the survey performed by Bilgin (2010) that $67 \%$ coniferous tree types and $33 \%$ broad leaved tree types are preferred. It is mentioned that the coniferous tree and broad leaved tree types in this preference show similarity to the Europe, but no rate of preference has been stipulated for this (Dimter, 2005; Bilgin, 2010).

In Fig. 1, the development of edge glued wood panel production in Europe between years 1990 - 2001 is shown. According to the data; the production amount that was $400.000 \mathrm{~m}^{3}$ in year 1990 has continuously increased and reached to $450.000 \mathrm{~m}^{3}$ in year 1993, $600.000 \mathrm{~m}^{3}$ in year $1995,750.000 \mathrm{~m}^{3}$ in year 1997 , $710.000 \mathrm{~m}^{3}$ in year 1999 and $650.000 \mathrm{~m}^{3}$ in year 2001 . The reason of the decrease seen here in the production after the year 1997 is explained as the change of edge glued wood panel production from Western Europe to Eastern Europe. In the same study where the development of the edge glued wood panel demand has been determined, it has been detected that the increase in the edge glued wood panel demand is higher than the increase in the production supply (Fig. 2).

In Fig. 2 are reviewed, it is seen that the demand accepted as $100 \%$ in year 1992 within the frame of the European Union has increased and reached to $220 \%$ in year $1993,280 \%$ in year $1995,380 \%$ in year 1995, 500\% in year 1999 and 550\% in year 2000 . The center of this high demand has been determined as Eastern Europe countries rather than Europe according to the same survey.

According to these studies performed for the production amounts in Europe, it is understood that the total production capacity in Europe is approximately 22.5 million $\mathrm{m}^{3} /$ year (Dimter, 2005). The latest data that have been determined for the developments on the edge glued wood panel demand and supply in Europe are shown in the Fig. 3 (Bilgin, 2010).

It is seen that the supply amount decreased although the continuance of the demand for the edge glued wood panel in Europe. This case can be explained mentioned before, that the data result from a study covering Germany and Western Europe and that the production facilities there have been closed and the production moved to the Eastern Europe. Therefore, this development is important since the edge glued wood panel in continuous demand increase is an industry open to investment and competition within Turkish forestry products industry (Dilik, 2005).

Edge glued wood panel quality classes and dimensions: As classification criterion in edge glued wood panel; initially the type of the tree (softwood hardwood), texture and color, the finger jointed or full size laths or lamellas are taken into consideration. Following these criterions, the statuses of the faults of the natural wood on the surfaces of the edge glued wood panels (for instance; knot, pith fleck, color differences, pitch pockets, annual ring widths, bark pockets, cracks, decays and damages by insects,...) are considered and they are divided into 5 separate quality classes according to their availability on both of the surfaces. These are set as $\mathrm{A} / \mathrm{A}, \mathrm{A} / \mathrm{B}, \mathrm{B} / \mathrm{B}, \mathrm{B} / \mathrm{C}$ and $\mathrm{C} / \mathrm{C}$ quality classes and the specifications of these quality classes are given in the standard regarding the edge glued wood panel (Dilik, 2005; Güngör and Kahveci, 2001).

One of the main factors determining the dimensions in the edge glued wood panel production is the size of the edge glued wood panel presses. The sizes of the presses that are manufactured throughout the world for this purpose are 2,5-3,0-3,5-4,2-4,5-5,5 and $6 \mathrm{~m}$. As parallel to these sizes, the productions are realized through keeping widths fixed as 1,0-1,3 m. However, with the developing technology, the edge glued wood panels with wider widths can be manufactured in the continuous presses. But the edge glued wood panels that are demanded today are generally used as furniture elements and therefore 45$55-60-90 \mathrm{~cm}$... widths are preferred more. Concerning the thickness of the edge glued wood panels, they can be manufactured as standard from 10-60 mm thickness. Today, the most demanded thickness in the world and Turkey are 16-19-30 and $42 \mathrm{~mm}$. (Güngör and Kahveci, 2001; Yongapanel, 2009; Bilgin, 2010).

The values foreseen for the size tolerances of the edge glued wood panels have been determined through the standards and the important size tolerances can be mentioned as following (Dilik, 2005):

- Length and width: $\pm 1,0 \mathrm{~mm} / \mathrm{m}$

- Thickness, for each panel: $\pm 0,3 \mathrm{~mm}$, for each production party: $\pm 0,4 \mathrm{~mm}$

- Deviation from smoothness of the edge: $1 \mathrm{~mm} / \mathrm{m}$

- Deviation from rectangularity (squareness tolerance): $1 \mathrm{~mm} / \mathrm{m}$

- Deviation from surface smoothness: $1,5 \mathrm{~mm} / \mathrm{m}$ 
Am. J. Applied Sci., 9 (10): 1625-1635, 2012

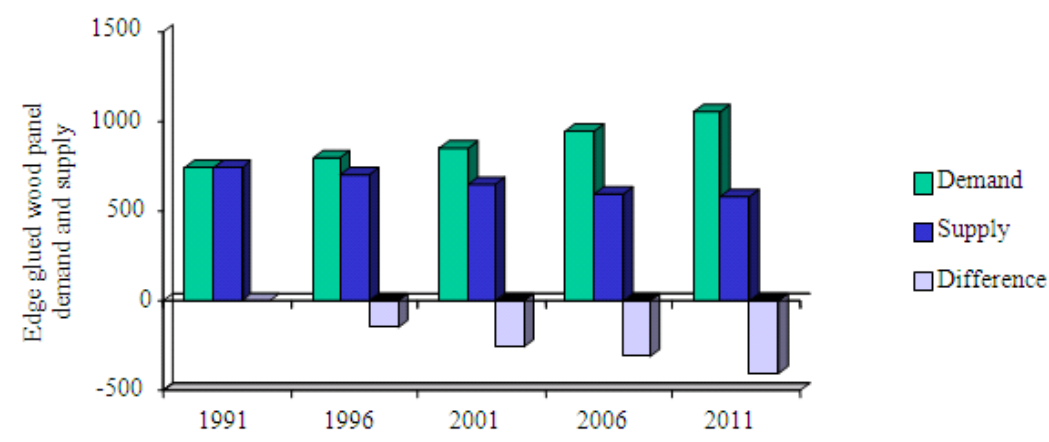

Fig. 3: The demand and supply for edge glued wood panel in Europe per years (Bilgin, 2010)

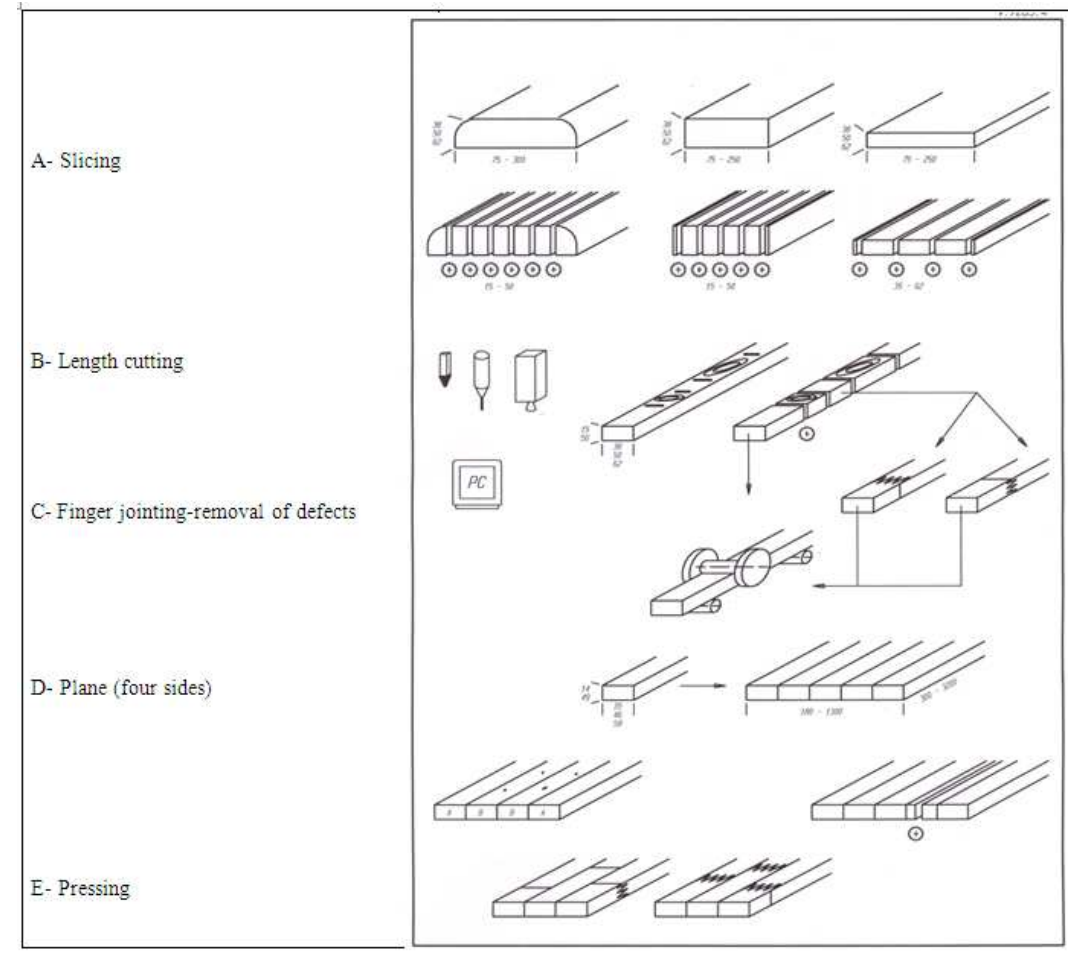

Fig. 4: The general production phases of edge glued wood panel (Dilik, 2009; Dimter and Weinig Group, 2010)

Table 2: Basic standards applied in terms of edge glued wood panel industry in Europe and Turkey (Bilgin, 2010; Dimter, 2010; TSE, 2010)

\begin{tabular}{llr}
\hline Standard & Subject & Year \\
\hline DIN EN 12 775 & Solid wood panel classification and terminology standard & 1997 \\
DIN EN 13 017 & Surface quality and appearance standard for & 1998 \\
& the coniferous and broad leaved tree & 1999 \\
DIN EN 13 353 & Standards for the utilization of solid wood panels & \\
& 1-For utilization in dry places & 2-For utilization in places in contact with water \\
& 3-For utilization on external surfaces & 1998 \\
DIN EN 13 354 & Gluing standard in solid wood panel production & 1999 \\
TS EN 324-1, & Assignment of Panel Sizes & 1999 \\
TS EN 324-2 & Assignment of Deviation from Miter and Edge Straightness & 1999 \\
TS EN 386 & Performance Features and Minimum Production Conditions & 2007 \\
TS EN 13353 & for Glued Laminated Wood Material & \\
\hline
\end{tabular}


In this study, the standards that have been determined for the technical specifications and utilization areas of the edge glued wood panels and the information related to these standards are given in Table 2.

Technology preferences in edge glued wood panel production: As a developing industry, the edge glued wood panel production exhibits a feature having production lines and machines easily getting complied with the innovations in the production technology when compared to the other sectors. Due to today's changing market and competition conditions, it is inevitable to manufacture different sizes and different types of edge glued wood panels and therefore it is a must for the production factories and the machines to have flexible production systems. Figure 4 shows that, the general work flow of the edge glued wood panel production as of the drying of the wood is basically formed of; slicing length cutting, finger jointing, planer and pressing phases. If we consider the basic principles of these production phases and the preference status of the industry in terms of latest technological innovations; it is seen that the investment preferences are generally on the machine and production lines having optimization systems (Nicholls, 2010; Dilik, 2009; Makel Machine, 2009; Ligno Machine, 2009; Smith and Araman, 1997).

Slicing: This phase is ultimately important for edge glued wood panels to be made of some certain tree species, therefore the classification is performed according to the appearance of the obtained lamella's wide surface and whether it will be subjected to full size or fault correction process or not. With the aid of the latest technological developments, mostly Slicing machines, which distinguish more quality classes and increase the efficiency and profit through providing recycling of the material with those features, are preferred in this phase. For instance; with the aid of the Quickfix-fixation system in the new system of Raimann as the slicing machine, the advantages of width optimization can be provided for the material (Raiman and Wenig Group, 2005; Dilik, 2009).

Length cutting: This process can be performed manually or through computer aided machines. The main objective in this phase is to have single part length at optimal sizes and send less material possible to finger jointing. It is a truth that when compared to the manual cutting, the waste material will be larger when we try to obtain a length according to the order and the performance difference here can be seen clearly with the help of the computer. Therefore, concerning this phase, it is seen that the computer aided length cutting machines are preferred in the industry. For instance; it is stated that the same amount length cutting process performed with the computer aided Opticut Series machines of Dimter Group provides $15 \%$ material saving when compared to the process performed manually (Dilik, 2009).

Finger jointing-removal of defects: In this phase, some of the enterprises use full size lamellas-laths without finger joint for the production of edge glued wood panels. However, most of the companies in the edge glued wood panel industry use finger jointed lamellas in the production of edge glued wood panels since most of the edge glued wood panels been glued with finger joint are technically more stabile and provide advantages through great recycling with different size options resulting from optimization.

Parallel to the technological developments and with the innovations in the finger joint technology, it is seen that even at least $15 \mathrm{~cm}$ short parts can be used too. Therefore, it makes the opticut-length cutting processes more efficient. For instance; when finger joint is added to the edge glued wood panel production under the content of the length cutting process, it has been determined that $6.5 \%$ additional efficiency is obtained (Grecon and Weinig Group, 2005; Dilik, 2009).

Plane (four sides): The lamellas to be pressed, particularly the surfaces to be glued, should be fully parallel to each other and the adjacent edges should be vertical to each other according to the section of the lamella. In this phase, although planing machines are used in the production, it is seen that recently the profile machines having five or more cutters and operation sensitivity $( \pm 0.05 \mathrm{~mm})$ higher than such machines are more preferred (Dilik, 2009).

Edge glued wood panel press-pressing: In this phase, the features of the press unit, which is a critical machine as determinant in the production capacity of the factory, come to the forefront. As known, it should not be disregarded that a high capacity production can be possible with a short term press. However, it should be kept in mind that all these details are associated with the optimal press time. For instance; it is seen that recently the edge glued wood panel presses having heating system with high frequency generator are more preferred than the classical edge glued wood panel presses with water, oil and electric heating (Dimter, 2005; Dilik, 2009).

Utilization areas of edge glued wood panel: The edge glued wood panel is used and recommended as an alternative to the other panel products for the furniture and decoration works in every field with its production technology that is able to catch the flexibility against the demand levels changing parallel to the recent economic and technical developments. 
Am. J. Applied Sci., 9 (10): 1625-1635, 2012

Table 3: Utilization areas of edge glued wood panel and the recommended tree types (Flynn and Holder, 2001; Bilgin, 2010)

\begin{tabular}{ll}
\hline Utilization areas & Appropriate/recommended tree types \\
\hline Production of school furniture & Beech, Chestnut, Oak, Poplar, Spruce, Scotch Pine, Fir \\
Furniture production & Beech, Chestnut, Oak, Walnut, Ash, Poplar, Cherry, Pear, Lime, Silverbirch, \\
& Spruce, Scotch Pine, Fir, Larix, Sapelli, Iroko, Teak, Limba, Wenge, Bubinga \\
Internal elements of wooden houses & Beech, Oak, Spruce, Scotch Pine, Fir, Larix \\
Production of toys & Beech, Chestnut, Oak, Walnut, Ash, Poplar, Cherry, \\
& Pear, Lime, Silverbirch, Spruce, Scotch Pine, Fir, Iroko \\
Parquet & Beech, Oak, Spruce, Scotch Pine, Fir, Larix \\
Production of stairs & Beech, Chestnut, Oak, Walnut, Ash, Cherry, Silverbirch, \\
& Spruce, Scotch Pine, Fir, Larix, Sapelli, Iroko, Teak, Limba, Wenge \\
Wall and interval separation panels & Spruce, Scotch Pine, Fir, Larix \\
Gyms & Ash, Silverbirch \\
Yacht decoration & Chestnut, Oak, Sapelli, Iroko, Teak, Limba Wenge, Bubinga \\
Frame of sitting groups & Beech, Spruce, Scotch Pine, Fir \\
As filling material & Poplar, Spruce, Scotch Pine, Fir \\
In carrier I beam production & Spruce, Scotch Pine, Fir, Larix \\
Bread and meat cutting benches & Beech, Chestnut, Oak, Walnut, Ash \\
Cafeteria tables' surfaces & Beech, Chestnut, Oak, Walnut, Ash, Cherry, Pear, Silverbirch, \\
& Spruce, Scotch Pine, Fir, Sapelli, Iroko, Teak, Limba, Wenge \\
Production of accessories & Oak, Walnut, Ash, Cherry, Pear, Lime, Silverbirch, Spruce, \\
& Scoth Pine, Fir, Teak, Wenge, Bubinga \\
Decoration of stores & Chestnut, Oak, Walnut, Ash, Cherry, Pear, Lime, Silverbirch, \\
& Spruce, Scotch Pine, Fir, Sapelli, Iroko, Teak, Limba Wenge, Bubinga \\
Production of laths and skirting boards & Poplar, Spruce, Scotch Pine, Fir, Larix \\
Kitchen benches & Beech, Chestnut, Oak, Walnut, Ash, Cherry, Teak \\
Outdoor furniture & Chestnut, Oak, Spruce, Scoth Pine, Fir, Larix, Sapelli, Iroko, \\
& Teak, Limba, Wenge \\
Production of doors & Beech, Chestnut, Oak, Walnut, Spruce, ScotchPine, Fir, \\
& Larix, Limba \\
Production of antique products & Chestnut, Spruce, Scotch Pine, Fir, Larix \\
\hline
\end{tabular}

The utilization areas of the edge glued wood panel and the tree types appropriate for those utilization areas are as shown in Table 3.

General structure of turkish edge glued wood panel industry: As parallel to the development and demand increase in Europe, it is seen that the edge glued wood panel production becomes an industry within Turkish forest products industry through being open to development and investment. Yet, while the number of the factories manufacturing edge glued wood panel until 2000 was 3 , this number has increased to 8 in year 2005 , to 18 in year 2008 and to 30 in year 2010. With this number of factories as well as the new investment and revision studies performed in the recent years, the edge glued wood panel industry in Turkey has reached to a competitive level both for quality and quantity in the edge glued wood panel production like in the other wood based panel products (mdf and particle board) as the edge glued wood panel industry production capacity in Turkey as well as World and Europe (Dilik, 2005; EPF, 2006; Demir, 2009; Bilgin, 2010).

From the data of the latest surveys, it has been determined that the total daily production capacity of Turkish edge glued wood panel production industry is $113 \mathrm{~m}^{3}$ and yearly is $40.000 \mathrm{~m}^{3}$. The allocation of the industrial facilities per the regions is shown in Table 4.
According to this, it is seen that the regional allocation of Turkish edge glued wood panel factories and their daily production capacities get intensifier in Marmara region under the impact of direct geographical closeness to the target markets, like in the other forest products industries of our country. This is followed by Aegean, Black Sea, Mediterranean and Middle Anatolia Region. There is no edge glued wood panel factory in the Eastern and Southeastern Anatolia Regions.

The data related to the allocation per the qualifications of the staff working in Turkish edge glued wood panel production industry are given in Table 5 and according to this, it has been understood that the rate of recruiting qualified workers in the manufacturing companies is high, but the rate of recruiting engineer, technician and marketing staff,... qualified staff is very low, therefore it can be revealed that the industry does not give the necessary importance for the qualifications of the staff in the industry.

According to the data obtained from the survey, the cost elements and their rates in the edge glued wood panel production are shown in Table 6 . According to this, it is seen that the most important share among the cost elements belongs to the raw material (43\%) and labor (18\%). 
Am. J. Applied Sci., 9 (10): 1625-1635, 2012

Table 4: The regional allocation of Turkish edge glued wood panel production (Bilgin, 2010)

\begin{tabular}{llr}
\hline Region & $\begin{array}{l}\text { No. of } \\
\text { Companies }\end{array}$ & $\begin{array}{l}\text { Production } \\
\text { capacity }\left(\mathrm{m}^{3} / 8 \mathrm{~h}\right)\end{array}$ \\
\hline Marmara & 13 & 58 \\
Aegean & 4 & 16 \\
Mediterranean & 2 & 10 \\
Middle Anatolia & 4 & 4 \\
Eastern Anatolia & 0 & 0 \\
Southeastern Anatolia & 0 & 0 \\
Black Sea & 7 & 21 \\
\hline
\end{tabular}

Table 5: The status of the staff working in Turkish edge glued wood panel production as of year 2009 (Bilgin, 2010)

\begin{tabular}{lr}
\hline Qualification of staff & Number of staff \\
\hline Engineer & 2 \\
Technician & 2 \\
Qualified Worker & 24 \\
Unqualified Worker & 17 \\
Commercial Staff & 4 \\
Total & 49 \\
\hline
\end{tabular}

Table 6: The costs elements of Turkish edge glued wood panel production (Bilgin, 2010)

\begin{tabular}{lc}
\hline Cost factor & $(\%)$ \\
\hline Energy & 6 \\
Raw material & 43 \\
Labor & 18 \\
Auxiliary materials & 10 \\
Marketing expenses & 15 \\
Others & 8 \\
\hline
\end{tabular}

Dimensions and quality classes of edge glued wood panel produced in turkey: It is seen that all types of edge glued wood panel at the sizes and quality classes mentioned in the standards on the edge glued wood panel quality classes and sizes are manufactured in Turkey and the data concerning the mostly manufactured edge glued wood panel sizes and quality classes in Turkish edge glued wood panel industry are shown in Table 7.

According to this, it is understood that each of the factories in Turkey determine their own measurements and quality classes through basing on their own production lines and particularly the dimensions of the edge glued wood panel presses and that they realize production at the size tolerances appropriate to the national and international standards. However, according to Bilgin (2010), it has been determined that basing on the national and international standards during the production by the industrial companies is very low $(36.6 \%)$. Furthermore, it has been determined that only one company has the greatest edge glued wood panel press in the market and that this company can manufacture edge glued wood panel till $5000 \mathrm{~mm}$ length (Bilgin, 2010).
It is revealed that the types of the tree species preferred in the edge glued wood panel utilization in Turkey are parallel to the preferences in the World and Europe and that these tree type preferences are shaped completely according to the requests of the consumers. According to Bilgin (2010), this case can be seen in the preferences of tree species in the edge glued wood panels used for the furniture and door frame production given in Table 8.

The impact factors forming the reasons why the edge glued wood panel users in Turkey prefer the edge glued wood panel and the impact rates of these on the preferences have been determined in a survey conducted by Bilgin (2010) and it is seen that they are (28\%) and mechanical resistance (28\%) according to their priority. Other reasons of preference are as following in sequence; quality (22\%), functionality $(11 \%)$, variety and opportunity to make selection (4\%).

On the other side, the reasons why the edge glued wood panel is preferred in the door production where the edge glued wood panel is mostly used in Turkey have been listed as following in sequence; because of more qualified production (55\%), because it facilitates the production (36\%) and because it is economic (9\%). Furthermore, it has been determined that the edge glued wood panel is mostly preferred in the production of door frame $(50 \%)$ and then used in the production of case panel $(25 \%)$, solid wood door production $(15 \%)$ and laths and skirt boards production (5\%) (Bilgin, 2010).

Supply and selection of edge glued wood panel by users in turkey: As the supply method for the edge glued wood panel of the edge glued wood panel users in Turkey, it has been determined that most of them generally purchase the edge glued wood panel as ready (70\%) and less prefer to order production (30\%).

According to Bilgin (2010), as the issues that the users in Turkey consider during the selection of the edge glued wood panel, they base on the price and quality together (90\%) and not consider price and quality as different factors for the selection. The allocation of the problems which the users face are as following in sequence; the price problem $(42 \%)$, the applicability problems $(41 \%)$ and the quality problems $(17 \%)$. Without any doubt, the utilization areas of the edge glued wood panel have impact on this allocation rates. Because in the same study; the expensive price of the edge glued wood panel when compared to the other panel products by regards of door, furniture,... parts carrying importance in terms of decoration, in other words the price is one of the reasons having the highest rate among the problems faced by the users. 
Am. J. Applied Sci., 9 (10): 1625-1635, 2012

Table 7: The sizes and quality classes of the edge glued wood panels used in Turkey (Dilik, 2005; Demir, 2009; Bilgin, 2010)

\begin{tabular}{|c|c|c|c|c|}
\hline $\begin{array}{l}\text { Company } \\
\text { Name }\end{array}$ & $\begin{array}{l}\text { Length } \\
(\mathrm{mm})\end{array}$ & $\begin{array}{l}\text { Width } \\
(\mathrm{mm})\end{array}$ & $\begin{array}{l}\text { Thickness } \\
(\mathrm{mm})\end{array}$ & $\begin{array}{l}\text { Quality } \\
\text { class }\end{array}$ \\
\hline Mobipan & $3000-5000$ & $1200-2050$ & $\begin{array}{l}14-18-22-24-27-32- \\
40-42-50-52-56\end{array}$ & $\begin{array}{l}\text { All quality classes as } \mathrm{A} / \mathrm{A}, \mathrm{A} / \mathrm{B} \text {, } \\
\mathrm{B} / \mathrm{B}, \mathrm{B} / \mathrm{C} \text { and } \mathrm{C} / \mathrm{C}\end{array}$ \\
\hline MPS & $2100-3050$ & 1210 & $\begin{array}{l}14-16-18-25-28- \\
35-38-42\end{array}$ & $\begin{array}{l}\text { All quality classes as } \mathrm{A} / \mathrm{A}, \mathrm{A} / \mathrm{B} \text {, } \\
\mathrm{B} / \mathrm{B}, \mathrm{B} / \mathrm{C} \text { and } \mathrm{C} / \mathrm{C}\end{array}$ \\
\hline Borpanel & $1500-4500$ & 1220 & $18-22-25-30$ & $\begin{array}{l}\text { All quality classes as } \mathrm{A} / \mathrm{A}, \mathrm{A} / \mathrm{B} \text {, } \\
\mathrm{B} / \mathrm{B}, \mathrm{B} / \mathrm{C} \text { and } \mathrm{C} / \mathrm{C}\end{array}$ \\
\hline Durpan & $1500-4000$ & 1250 & $16-18-25-30$ & $\begin{array}{l}\text { All quality classes as } \mathrm{A} / \mathrm{A}, \mathrm{A} / \mathrm{B} \text {, } \\
\mathrm{B} / \mathrm{B}, \mathrm{B} / \mathrm{C} \text { and } \mathrm{C} / \mathrm{C}\end{array}$ \\
\hline Horpan & $1200-2440$ & 1220 & $14-18-30-40$ & $\begin{array}{l}\text { All quality classes as } \mathrm{A} / \mathrm{A}, \mathrm{A} / \mathrm{B} \text {, } \\
\mathrm{B} / \mathrm{B}, \mathrm{B} / \mathrm{C} \text { and } \mathrm{C} / \mathrm{C}\end{array}$ \\
\hline Yongapanel & 4100 & $1000-1300$ & $12-16-19-26-30-40$ & $\begin{array}{l}\text { All quality classes as } \mathrm{A} / \mathrm{A}, \mathrm{A} / \mathrm{B} \text {, } \\
\mathrm{B} / \mathrm{B}, \mathrm{B} / \mathrm{C} \text { and } \mathrm{C} / \mathrm{C}\end{array}$ \\
\hline Europan & $1000-3500$ & 1220 & $18-25-30-40$ & $\begin{array}{l}\text { All quality classes as } \mathrm{A} / \mathrm{A}, \mathrm{A} / \mathrm{B} \text {, } \\
\mathrm{B} / \mathrm{B}, \mathrm{B} / \mathrm{C} \text { and } \mathrm{C} / \mathrm{C}\end{array}$ \\
\hline Salkım & $3000-4100$ & $1000-1300$ & $12-16-18-22-25-30-40$ & $\begin{array}{l}\text { All quality classes as } \mathrm{A} / \mathrm{A}, \mathrm{A} / \mathrm{B} \text {, } \\
\mathrm{B} / \mathrm{B}, \mathrm{B} / \mathrm{C} \text { and } \mathrm{C} / \mathrm{C}\end{array}$ \\
\hline
\end{tabular}

Table 8: The preference status of the tree types in the edge glued wood panel utilization in Turkey (Bilgin, 2010)

\begin{tabular}{lll}
\hline Type of Tree & Preference rate $(\%)$ & Mostly used types \\
\hline Broad leaved Trees & 33 & Beech, Chestnut, Oak, Silverbirch, Ash, Sapelli, Iroko \\
Coniferous Tree & 67 & Spruce, Fir, Scoth Pine and Larix \\
\hline
\end{tabular}

As one of the areas where the edge glued wood panel is mostly used, the data obtained for determining in which production phases the edge glued wood panel utilization in the door industry is preferred show that the edge glued wood panel is mostly preferred in the production of case $(50 \%)$ and then the production of case panel $(25 \%)$, the production of solid wood door $(15 \%)$ and the production of skirt and border $(5 \%)$ (Bilgin, 2010).

\section{RESULTS}

When the edge glued wood panel is compared with the other wood panel products, its utilization areas gradually increase in the wood works, particularly in the furniture and door industry, with its superior specifications. In addition to the economical and technological developments, the improving living standards and the impact of the ecological approaches cause a trend to use the solid wood materials so this is one of the other reasons of the development of the edge glued wood panel industry as determined in various researches. It is seen that the edge glued wood panel industry is in a rapid development (Nicholls, 2010; Dilik, 2005; Ligno Machine, 2009; Makel Machine, 2009; Smith and Araman, 1997; EPF, 2006).

The edge glued wood panel industry has approximately 16 years background in our country. As in Europe, it is seen that the edge glued wood panel industry in our country is in a very fast development. The first edge glued wood panel facility in Turkey has been established in year 1994 and while only 3 companies were actively dealing with the production till year 2000, the number of the companies raised to 30 in year 2010. Against the supply decrease in Europe that still has 2-2.5 million $\mathrm{m}^{3}$ production capacities, it is seen that the demand increase continues. The total production capacity in Turkey is approximately 40,000 m³year (Bilgin, 2010; Dimter, 2005). While only 2-3 tree species were used in the edge glued wood panel industry previously, it is seen that this number reached to 20 species today. Furthermore, it has been determined that the edge glued wood panels made of coniferous tree types are mostly used in the furniture and door industry. The edge glued wood panels made of broad leaved tree species are preferred for the areas such as the stair, accessories, indoor and outdoor furniture as well as yacht and souvenir property productions (Bilgin, 2010).

\section{DISCUSSION}

It is seen that Turkish edge glued wood panel industry gets intensifier in the Marmara Region due to the reasons such as closeness to the market and the easy accessibility to the raw material. The industry is in an effort to make innovation and development investments as easy respond to every level of demand with the production technologies having flexible production systems similar to all edge glued wood panel companies in the world (Bilgin, 2010; Dilik, 2009; Ligno Machine, 2009; Makel Machine, 2009). 
Similar to the other forestry product industries, the staff working in the manufacturing companies in Turkey is very low in terms of technical staff and engineers (2\%) and the allocation of the cost elements in the edge glued wood panel production is as following; raw material $43 \%$, labor $18 \%$, power $6 \%$, auxiliary materials $10 \%$, marketing expenses $15 \%$ and other expenditures 8\% (Bilgin, 2010).

According to the results of the survey conducted for the companies using edge glued wood panel in their productions as consumer; it has been determined that the door frame manufacturers prefer edge glued wood panels made of coniferous tree types and the furniture and other product manufacturers prefer the edge glued wood panels that are made of broad leaved and tropical tree types.

In the production of furniture as the trends influence the customers, the edge glued wood panels are particularly preferred in baby and youth rooms since it is a healthy and ecological product. The impact factors forming the reasons of preferring the edge glued wood panel by the edge glued wood panel consumers in Turkey and their rate of impact on the preferences have been determined as following; esthetic (28\%), mechanical resistance feature $(28 \%)$, quality $(22 \%)$, functionality $(11 \%)$, variety and electability $(4 \%)$ and other factors $(7 \%)$. On the other side, it is seen that the edge glued wood panel using consumers prefer order production for door frame and the other consumers prefer the products ready at the stock. While $90 \%$ of the consumers purchase the edge glued wood panel, they consider the price and quality issues together.

Similar to the research results of Nicholls (2010) and $\operatorname{EFP}(2006)$, the allocation of the problems which the edge glued wood panel consumers face is as the following; the price problem (42\%), the applicability problems $(41 \%)$ and the quality problems $(17 \%)$. The utilization area of edge glued wood panels has absolute effect on these ratios. Because the expensive price of the edge glued wood panel when compared to the other panel products by regards of door, furniture, parts carrying importance in terms of decoration, in other words the price is one of the reasons having the highest rate among the problems faced by the users.

According to Bilgin (2010), the most important problem about the structure of the edge glued wood panel industry is the lack of communication between the manufacturers and consumers similar to the other sectors of Turkey. The edge glued wood panel manufacturers generally take decision without making any market and demand survey and therefore they mostly work at high costs and under their production capacities. On the other side, the manufacturer companies do not have any union or association that they have formed and this brings the unfair competition and quality problems in the sector.

\section{CONCLUSION}

As the result of this research, the utilization of the edge glued wood panels are progressively increasing because of the edge glued wood material's superiority when compared to the other materials and its specification to meet any kind of constructive requirement with its high stability size and surface as well as the physical properties of structural construction. Furthermore, besides its production that is more economic and easy than the other panel products, its investment cost is approximately ten times less than the other panel products, therefore it receives demand and its market gets progressively wider. However, reaching to the specifications expected from the edge glued wood panel requires some certain conditions. As known, the economical production of a product, besides its quality, carries great importance due to the improving production systems.

The only way to enable the industry to continue its development with these features and stay active in the edge glued wood panel market is to realize production with the production lines providing compliance to the innovations in the production technology or the production realized with the machines having their own optimization systems. At the same time, the production should have the flexibility to respond to different order quantities, in other words to have flexible production systems in terms of efficiency. Furthermore, it can be said that today it is necessary to manufacture different sizes and types of edge glued wood panels as to meet every level of demand.

As a conclusion, the edge glued wood panel industry is a sector in Turkey that is being evaluated within a positive perception by the production industry and marketing industry with its dynamic structure open for development and investment.

\section{REFERENCES}

Bilgin, Y., 2010. Evaluation of structural status of solid wood panel sector in Turkey and utility possibilities in wood working Industry. MS.c Thesis, Istanbul University, Institute of Science, Istanbul, Turkey.

Nicholls, D.L., 2010. Alaska Birch for Edge-glued Panel Production: Considerations for Wood Products Manufacturers. 1st Edn., U.S. Department of Agriculture, Portland, pp: 25. 
Demir, S., 2009. Reviews on solid wood panel production technology, Its structural status and Its trade in Turkey. MS.c Thesis, Istanbul University, Istanbul, Turkey.

Dilik, T., 2005. Edge glued wood panel market and innovations in the production technology. Furniture Decoration Mag. Istanbul Turkey, 69: 292-304.

Dilik, T., 2009. Material revealing the solid wood privilege again-The solid wood, Wood Machinery. Technol. Res. Mag., 39: 50-53.

Dimter and Weinig Group, 2010. Weinig Group, Dimter Opticut 200 Elite Pictures.

Dimter, 2005. Technique documents of edge-gluing pres and cross cutting and optimisation systems for solid wood panels.

EPF, 2005. The eco-cycle of wood and wood based products. Annual Report 2005/06, European Panel Federation, 24.rue Montoyer box 20 B-1000, Brussels.

EPF, 2006. European Panel Federation 5th European Wood-Based Panel Symposium, 4-6 October 2006 Hanover, Germany, EFP General Secretariat box 5, B-1070, Brussels.

Flynn, J.H. and C.D. Holder, 2001. A Guide to Useful Woods of The World, 2nd Edn., Forest Products Research, ISBN-10: 1892529157, pp: 618.
Grecon and Weinig Group, 2005. Technique documents of finger jointing lines for solid wood panels.

Güngör, A. and M. Kahveci, 2001. Edge glued wood panel. Constr. Decoration Mag., 19: 92-100.

Kurtoglu, A., 2010. Furniture and wood constructions, unprinted course notes. Istanbul University, Bahcekoy, Istanbul, Turkey.

Ligno Machine, 2009. Edge glued wood panel production lines, wood machinery. Technol. Res. Maga., 39: 54-57.

Makel Machine, 2009. Solid wood production, wood machinery. Technol. Res. Maga., 39: 58-60.

Özkaya, K., 2007. determination of some physical and mechanical properties of Edge glued Wooden Panels (EWP) produced with various manufacturing techniques. Ph.D. Thesis, Gazi University, Institute of Science, Ankara, Turkey.

Raiman and Wenig Group, 2005. Technique documents of rip saws for the woodworking industry.

Smith, B. and P. Araman, 1997. Edge-glued panels and blanks offer value added opportunities. Newsletter, Virginia Forest Products Association.

TSE, 2010. Turkish standards institute. Ankara. Turkey, Yongapanel, A.Ş., 2009. Edge glued wood panel wood machinery. Technol. Res. Maga., 39: 70-72. 